\title{
Article
}

\section{Sympathetic Nerve Function Status in Obesity}

\author{
Shahin Akhter ${ }^{1}$, Noorzahan Begum², Sultana Ferdousi ${ }^{3}$, Shelina Begum ${ }^{4}$, Taskina Ali ${ }^{5}$
}

\begin{abstract}
Background: Obesity is an important and independent risk factor for cardiovascular morbidity and mortality. High incidence of cardiac autonomic nerve dysfunction has been noted in obese subjects who are at increased risk for sudden death Objective: To study the relationship between sympathetic nerve function and obesity. Methods: This cross sectional study was conducted in the Department of Physiology, Bangabandhu Sheikh Mujib Medical University between July 2006 to June 2007 and 40 apparently healthy obese subjects aged18-40 years of both sexes with BMI $\geq 25 \mathrm{~kg} / \mathrm{m}^{2}$ in study group. Age and sex matched 40 apparently healthy nonobese subjects with BMI range of $18.5-22.9 \mathrm{~kg} / \mathrm{m}^{2}$ were also included for comparison (Control). Two noninvasive cardiovascular reflex tests like blood pressure response to sustained handgrip and blood pressure response to standing were done to assess sympathetic nerve function status. Unpaired Student's ' $t$ ' test and Pearson correlation coefficient test were used for statistical analysis. Results: Mean values of resting heart rate, resting systolic and diastolic blood pressure were significantly $(\mathrm{p}<0.05)$ higher and both the sympathetic nerve function parameters(BP response to hand grip and BP response to standing) were significantly ( $\mathrm{p}>0.05$ ) lower in obese compared to those of non obese control subjects. Again, BP response to hand grip were negatively and BP response to standing were positively correlated with BMI in all subjects. These correlations are statistically significant $(\mathrm{p}<0.05)$. Conclusion: The results of this study revealed that sympathetic nerve function may be reduced in obesity.
\end{abstract}

Key words: sympathetic nerve function, obesity, BMI

J Bangladesh Soc Physiol. 2010 June; 5(1): 34-39 For author affiliations, see end of text.

http://www.banglajol.info/index.php/JBSP

\section{Introduction}

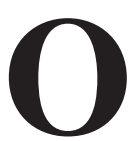

besity is one of the nutritional disease which is increasing at an alarming rate in underdeveloped countries ${ }^{1}$. Obesity leads to serious health consequences. It is a major risk factor for chronic diseases such as cardiovascular disease, diabetes, musculoskeletal disorder especially osteoarthritis and some cancers like endometrial, breast and colon ${ }^{2}$.

Obesity is characterized by an excessive deposition and storage of fat in the body ${ }^{3}$. Body mass index (BMI) is the marker for body fat content ${ }^{4}$.
WHO has set standards for overweight and obesity by BMI $\geq 25 \mathrm{~kg} / \mathrm{m}^{2} \& \geq 30 \mathrm{~kg} / \mathrm{m}^{2}$ respectively. But, the BMI cut off point for overweight $\geq 23 \mathrm{~kg} / \mathrm{m}^{2}$ and obese $\geq 25 \mathrm{~kg} / \mathrm{m}^{2}$ for Asians are lower than the WHO criteria ${ }^{5}$.

Homeostatic mechanisms maintain body weight within a narrow range ${ }^{1}$. Fat deposition results from discrepancy between energy consumption and expenditure ${ }^{6}$. Autonomic nervous system dysfunction has been associated with obesity in humans and animals ${ }^{7}$. Disturbed sympathetic nerve function may be of importance in obesity;

J Bangladesh Soc Physiol. 2010 June; 5(1): 34-39 
sympathetic underactivity could contribute to deficient thermogenesis, positive energy balance and weight gain, while in contrast, sympathetic overactivity would predispose to the development of obesity related hypertension ${ }^{8}$. The relationship between decreased sympathetic activity and obesity has been observed in most animal studies ${ }^{9-10}$. Studies on autonomic nervous system in human obese persons have reported controversial findings; hypoactivity of parasympathetic and hyperactivity of sympathetic nerve function ${ }^{11}$, both lowered sympathetic and parasympathetic nerve activity $^{12-13}$, increased parasympathetic nerve activity with a decreased sympathetic nerve activity $^{14}$.

Obesity related health problems including various cardiovascular and metabolic diseases are not uncommon in our community. In addition to recognized complications of obesity, the probable association of autonomic nerve dysfunction with certain cardiovascular disorders may also exist in obese person. The outcome of this study may focus the need for management of obesity by various procedures including motivation for weight reduction.

To the best of our knowledge no such study on sympathetic nerve function status in obese people has been done in Bangladesh. Therefore, this study was carried out to observe the sympathetic nerve function status in obese subjects by 2 non invasive cardiovascular reflex tests and also to study the relationship between obesity and sympathetic nerve function.

\section{Methods}

This observational study was conducted in the Department of Physiology of Bangabandhu Sheikh Mujib Medical University, Dhaka, Bangladesh. For this, 80 apparently healthy subjects of both sexes in equal number with age range from18-40 years were selected from the different areas of Dhaka city. The subjects with age $>40$ years, overweight (BMI $23-24.9 \mathrm{~kg} / \mathrm{m}^{2}$ ),

J Bangladesh Soc Physiol. 2010 June; 5(1): 34-39 diabetes mellitus, chronic renal failure, any obvious cardiovascular diseases, chronic obstructive lung diseases, previous history of head injury and smokers were excluded from this study.

The subjects were divided into two groups by their body mass index. Group A was consisted of 40 nonobese subjects with BMI between 18.50 $22.90 \mathrm{~kg} / \mathrm{m}^{2}$ and Group B was consisted of obese subjects with $B M I \geq 25 \mathrm{~kg} / \mathrm{m}^{2}$.

The purpose and procedure of the study were explained to each subject. Written informed consent was obtained from each subject. Study protocol was approved by ethical committee of the Department of Physiology BSMMU.

Detailed medical and family history was recorded in a preformed questionnaire. Height and weight of the subjects were recorded and BMI was calculated. Random blood samples were collected to determine blood glucose and serum creatinine to exclude diabetes mellitus and chronic renal failure. Blood glucose and serum creatinine level were measured by auto analyzer in the hematology laboratory of the department of Physiology. Then the sympathetic nerve function was assessed by two non invasive cardiovascular reflex tests using sphygmomanometer and an inflated calf.

Each of the subjects was briefed about the detail of the procedure and encouraged to obtain maximum efficient performance. 2 non invasive cardiovascular reflex tests; BP response to sustained hand grip (Isometric exercise test) and BP response to standing(Orthostatic test) were conducted in the neurophysiology laboratory of the department of Physiolog BSMMU between 9.00am and 2.30pm in a comfortable environment. The subjects were allowed to take rest and relax for at least 10 minutes upon arrival. In all subjects, blood pressure response to sustained handgrip and to standing were performed by using sphygmomanometer. Before the tests, all the subjects rested in supine position for a minimum 
Article

of 10 minutes. Resting heart rate and resting systolic and diastolic pressure of all subjects were recorded.

\section{Blood pressure response to sustained handgrip} test (rise in DBP):

The subjects were asked to sit quietly and their blood pressure was measured. Then they were asked to grip the inflated cuff of a sphygmomanometer at $30 \%$ of the maximum voluntary contraction for maximum 5 minutes and then again blood pressure was measured.The difference of diastolic blood pressure between the resting and just before the release of handgrip was calculated. Rise of diastolic blood pressure (DBP) 16 or greater would be regarded as normal, 11-15 as borderline and 10 or below as abnormal $^{15}$.

\section{Blood pressure response to standing (fall in SBP):}

The subjects were asked to lie on bed. After 10 minutes rest, their blood pressure was measured by the sphygmomanometer. Then they were asked to stand up as quickly as possible with pressure cuff tied around the arm. Again their blood pressure was measured. The differences in systolic blood pressure between lying and 1 minute after standing was calculated.

Fall of SBP 10 or below was taken as normal, 1119as borderline and 30 or more as abnormal. ${ }^{15}$

Analysis of the data was done by using computerized SPSS program version-12. All the data were expressed as mean \pm SD (Standard deviation). For statistical analysis unpaired Student's 't' test and Pearson's correlationcoefficient test was used as applicable. P value $<0.05$ was accepted as significant.

\section{Results}

Both groups are matched for age, sex and height. But the mean BMI were significantly higher $(p<0.001)$ in obese subjects compared to those of nonobese control subjects. (Figure 1)

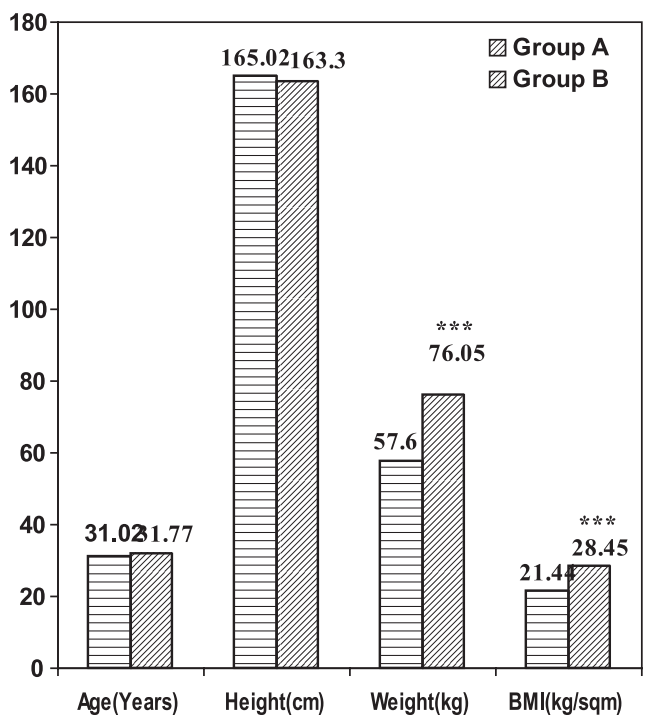

Group A : Nonobese . *** $=p<0.001$

Group B : Obese .

Figure 1: Mean age, height, weight and BMI in the study groups $(n=80)$

Mean resting pulse rate, systolic and diastolic blood pressures were significantly higher $(\mathrm{p}<0.01)$ in obese subjects. (Table I).

Table I: Resting pulse rate and blood pressures in different groups $(\mathrm{n}=80)$

\begin{tabular}{lcc}
\hline Parameters & $\begin{array}{c}\text { Group A } \\
(\mathrm{n}=40)\end{array}$ & $\begin{array}{c}\text { Group B } \\
(\mathrm{n}=40)\end{array}$ \\
\hline $\begin{array}{l}\text { Pulse rate } \\
\text { (beats/min) }\end{array}$ & $72.27 \pm 4.18$ & $75.37 \pm 4.37^{* *}$ \\
$\begin{array}{l}\text { Systolic blood } \\
\text { pressure (mm Hg) }\end{array}$ & $113.13 \pm 7.56$ & $118.12 \pm 6.27^{* *}$ \\
$\begin{array}{l}\text { Diastolic blood } \\
\text { pressure (mm Hg) }\end{array}$ & $70.12 \pm 6.93$ & $73.75 \pm 5.94^{*}$ \\
\hline
\end{tabular}

Data expressed as mean \pm SD

Group A : Nonobese

Group B : Obese

$\mathrm{n}=$ total number of subjects.

$*$ =significant at $<0.05$ level.

${ }^{* *}=$ significant at $<0.01$ level.

J Bangladesh Soc Physiol. 2010 June; 5(1): 34-39 
In blood presure response to sustained hand grip the mean rise in diastolic blood pressure(DBP) was significantly lower $(\mathrm{p}<0.05)$ in group $B$ than those of group A.

Table II: BP response to sustained handgrip in different groups $(n=80)$

\begin{tabular}{lcc}
\hline $\begin{array}{l}\text { DBP } \\
(\mathrm{mm} \text { of } \mathrm{Hg})\end{array}$ & $\begin{array}{c}\text { Group A } \\
(\mathrm{n}=40)\end{array}$ & $\begin{array}{c}\text { Group B } \\
(\mathrm{n}=40)\end{array}$ \\
\hline Before handgrip & $70.12 \pm 6.93$ & $70.75 \pm 5.96$ \\
After handgrip & $90.77 \pm 8.44$ & $92.35 \pm 5.87$ \\
Increase after & $20.7 \pm 3.58$ & $18.60 \pm 3.17^{*}$ \\
handgrip & & \\
\hline
\end{tabular}

Data expressed as mean \pm SD

Group A : Nonobese

Group B : Obese

$\mathrm{n}=$ total number of subjects.

$*=$ significant at $<0.05$ level.

Again in blood pressure response to standing, mean value of fall in systolic blood pressure(SBP) was significantly higer $(\mathrm{p}<0.05)$ in group $B$ than those of group A.

Table III: BP response to standing in different groups $(\mathrm{n}=80)$

\begin{tabular}{lcc}
\hline $\begin{array}{l}\text { SBP } \\
(\mathrm{mm} \text { of } \mathrm{Hg})\end{array}$ & $\begin{array}{c}\text { Group A } \\
(\mathrm{n}=40)\end{array}$ & $\begin{array}{c}\text { Group B } \\
(\mathrm{n}=40)\end{array}$ \\
\hline Lying & $113.13 \pm 7.56$ & $118.12 \pm 6.27$ \\
After standing & $109.3 \pm 7.15$ & $112.52 \pm 1.41$ \\
Fall after standing & $4.32 \pm 2.05$ & $5.65 \pm 2.25^{*}$ \\
from lying & & \\
\hline
\end{tabular}

Group A : Nonobese

Group B : Obese .

$*$ = significant at $<0.05$ level.

Again in correlation test, the rise of DBP in hand grip test showed negative and fall in SBP in J Bangladesh Soc Physiol. 2010 June; 5(1): 34-39 standing showed positive correlation with BMI in both groups and these relationships were statistically significant.(p<0.05)(Figure 2 \& 3)

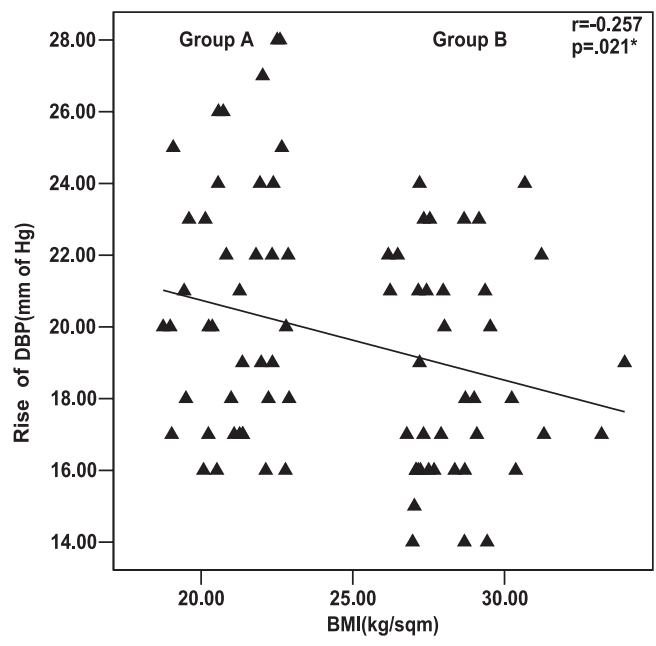

Figure 2: Relationship between BMI and sustained handgrip (rise of DBP) in both groups.

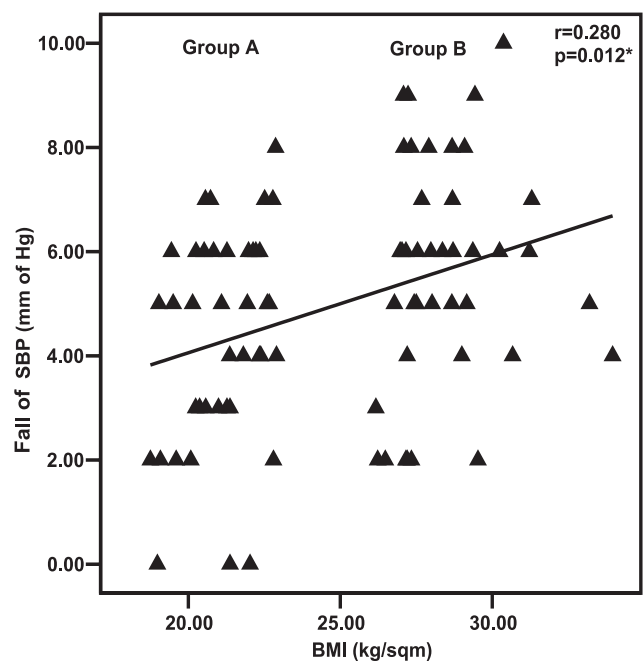

Group A: Nonobese

Group B: Obese $*$ Significant at $\mathrm{p}<0.05$

Figure 3: Relationship between BMI and fall of systolic blood pressure after standing from lying in both groups $(n=80)$ 


\section{Article}

\section{Discussion}

In the present study, resting heart rate, resting systolic and diastolic blood pressures were significantly higher in obese than those in non obese subjects but these values were within normal Physiological limit. Similar observations were also made by some other investgators. ${ }^{16}$

Again, the observed lower blood pressure response to handgrip and standing indicated lower sympathetic nerve activity in obese person compared to non obese. These findings are consistent with those made by some investigators on human studies and also on obese animal models ${ }^{17-19}$. Again, significant negative correlation of rise of DBP and significant positive correlation of fall of SBP with BMI also showed association of lower sympathetic nerve function with obesity. ${ }^{5}$

. In the present study, the lower response of BP in handgrip and standing is suggestive of reduced sympathetic nerve function in obesity which is further supported by their significant negative and positive correlation respectively with BMI. There is evidence that impairment of sympathetic nerve activity might occur in obese persons which could explain partly the strong relationships among obesity, dangerous arrhythmia and sudden death ${ }^{9}$. Peterson et al. observed that sympathetic nerve activity was decreased with increasing percentage of body fat $^{7,21}$. In contrast, some group of investigators noted that obesity in human being is associated with marked sympathetic nerve overactivation ${ }^{21}$. Some investigators expressed their view regarding increase in resting heart rate and blood pressure in obese person which might result from a higher sympathetic tone induced by hyperinsulinaemia ${ }^{16}$ and. higher level of catecholamine $^{20}$.

Reduced sympathetic nervous activity has been highlighted as a potential mechanism predisposing to body weight gain in human ${ }^{8}$. It has been suggested that decreased sympathetic activity may be the primary reason for excessive
Sympathetic Function in Obesity

energy storage ${ }^{18}$. However, the exact mechanisms involved for the impairment of sympathetic nerve function in obese subjects of the present series cannot be elucidated from this type of study. According to the suggestions made by different investigators decreased sympathetic activity may be due to the defect in sympathetic nerve activation or in peripheral adrenoreceptors ${ }^{21}$. Again the higher resting heart rate and systolic and diastolic blood pressure in obese subjects may be due to hyperinsulinemia ${ }^{16}$ and higher catecholamine level ${ }^{20}$. However, it was not possible to comment on all these factors as none of these were studied in this work. In obese persons serious health problems may be seen if current ANS stress increases. This may not be compensated.

\section{Conclusion}

From the result of this study, it can be concluded that sympathetic nerve function may be reduced in obesity.

\section{Author affiliation :}

1. *Shahin Akhter, Lecturer, Department of Physiology, Chittagong Medical College, Chittagong .Email: Shahinakhterakhter@yahoo.com

2. Noorzahan Begum, Professor Department of Physiology, Bangabandhu Sheikh Mujib Medical University(BSMMU), Bangladesh, Email: noorzahanbeg@yahoo.com

3. Sultana Ferdousi, Assistant professor, Department of Physiology, Bangabandhu Sheikh Mujib Medical University (BSMMU), Bangladesh, Email: sferdousiratna@gmail.com

4. Shelina Begum. Professor, Chairman, Department of Physiology, Bangabandhu Sheikh Mujib Medical University(BSMMU), Bangladesh.

5. Taskina Ali, Assistant Professor, Department of Physiology, Bangabandhu Sheikh Mujib Medical University(BSMMU), Bangladesh, Email:taskinadr@ gmail.com

*for correspondence

\section{References}

1. Kretser DD, Grosom AB, Marshell JC, Melmed S, Potts JT, Weir GC. Endocrinology. $5^{\text {th }}$ ed.USA: Elsevier Saunders; 2006. 256 p.

2. Ganong WF. Review of Medical Phisiology. 22nd ed. USA: Mc Graw- Hill Company; 2005. 211 p.

J Bangladesh Soc Physiol. 2010 June; 5(1): 34-39 
3. Yakinci C, Mungen B, Karabiber H, Tayfun M, Evereklioglu C. Autonomic Nervous system functions in obese children. Brain Dev. 2000; 22:151-53.

4. Guyton AC, Hall JE. Text book of medical physiology. $11^{\text {th }}$ ed. Singapore: W.B.Saunders; 2006. 506p.

5. Steering Committee. The Asia-Pacific perspective: Redefining obesity and its treatment. Melbourne: International Diabetes Institute, 2000.

6. Frier BM, Truswell AS, Shepherd J, Jung R. Nutritional and metabolic disorders. In:Haslett C, Chilvers ER, Hunter JAA, Boon NA, editors. Davidson's principles and practice of Medicine. United Kingdom: Churchill livingstone; 2002.p.301-6.

7. Valensi P, Smagghue O, Paries J, Velayoudon P, Lormeau B, Attali JR. Impairment of skin vasoconstrictive response to sympathetic activation in obese patients: Influence of rheological disorder. In J obs 2000;49:600-6.

8. Vaz M, Jennings G, Turner A, Cox H, Lambert G and Esler M. Regional sympathetic nervous activity and oxygen consumption in obese normotensive human subjects.Circulation. 1997;96:3423-29.

9. Bray GA and York DA. Hypothalamic and Genetic obesity in Experimental Animals: An autonomic and endocrine hypothesis. Physiol Rev. 1979; 59: 719-29.

10. Bray GA. Obesity-A disease of nutrient or energy balance? Nutr Rev. 1987;45:33-43.

11. Arrone LJ, Mackintosh R, Rosenbaum M, Liebel RL, Hirsch J. Autonomic nervous system activity in weight gain and weight loss. Am J Physiol. 1995; 269: R222- R225.

12. Hofmann KL, Mussgay L, and Ruddel H. Autonomic cardiovascular regulation in obesity. J Endocrinol. 2000;164: 59-66.
13. Peterson HR, Rothschild M, Weingberg CR, Fell RD, Meleish KR, Pfeifer MA. Body fat and the activity of autonomic nervous system. N Eng J Med. 1988; 28:1077-83.

14. Bray GA. Auotonomic and endocrine balance in the regulation of energy balance. Fed Proc. 1986; 45: $1404-10$.

15. Mathias CJ and Bannister R. Autonomic failure. A textbook of clinical disorders of the autonomic nervous system. $3^{\text {rd }}$ ed. Newyork: Oxford University Press; 1992. 702 p.

16. Valensi P, Nguyen TN, Idriss S, Cazes P, Karam G, Paries J, Miossec P and Attali JR. Influence of parasympathetic dysfunction and hyperinsulinaemia on the haemodynamic response to an isometric exercise in non insulin dependent diabetes mellitus. Metabolism. 1998; 47: 934-39.

17. Colak R, Donder E, Karaoglu A, Ayhan O, Yalniz A. Obesity and the activity of autonomic nervous system. Turk J Med Sci. 2000; 30: 173-76.

18. Rossi M, Marti G, Ricordi L, Fornasari G, Finardi G, Fratino P, and Bernardi L. Cardiac autonomic dysfunction in obese subjects. Clin Sci. 1989; 76: 567-72.

19. Valensi P, Bich Ngoc PT, Idriss S, Paries J, Cazes P, Lormeau B and Attali JR. Haemodynamic response to an isometric exercise test in obese patients: Influence of autonomic dysfunction. Int J obs. 1999; 23:543-49.

20. Kim JA, Park YG, Cho KH, Hong MH, Han HC, Choi YS et al. Heart rate variability and obesity indices: Emphasis on the response to noise and standing. J Am Board Fam Prac. 2005; 18: 97-103.

21. Valensi P, Lormeau B, Dabbech M, Miossec P, Paries J, Dauchy F et al., Glucose induced thermogenesis, inhibition of lipid oxidation rate and autonomic dysfunction in non- diabetic obese women. Int J obs. 1998; 22:494-99. 